\title{
Individuals progressive tension protocol in the application of elastic bandage in nonspecific chronic low back pain: a case study
}

\author{
Ana Carolina Ferreira Tsunoda Del Antonio1, Giani Alves de Oliveira1', Marieli Ramos Stocco², Tiago \\ Tsunoda Del Antonio ${ }^{1}$, Rodrigo Carvalho Andraus ${ }^{2}$.
}

${ }^{1}$ Universidade Estadual do Norte do Paraná - UENP, Jacarezinho - PR, Brasil; ${ }^{2}$ Universidade Pitágoras UNOPAR, Londrina - PR, Brasil.

\begin{abstract}
Background: Low back pain (LBP) is a disorder of musculoskeletal origin of multifactorial character, which can become chronic when it persists for more than 3 months. It is expected that $80 \%$ of the world's population will present with LBP at some stage of life, characterizing it as a serious public health condition that requires specific interventions for treatment. Given the context, elastic banding arises, a resource that can be useful to these patients, however, its effectiveness requires that the bandage be of quality that the therapist has experience and that its application is standardized, the latter being scarce in the current literature. Thus, the present study sought to observe what would be the application of a progressive tension protocol with elastic bandage in an individual with nonspecific chronic LBP. Methods: A 47-year-old female, caregiver of the elderly and diagnosed with nonspecific chronic LBP participated in the study. The treatment protocol lasted 10 weeks, where the elastic bandage was applied to the participant and in the first and last session, in addition to the report of the level of pain obtained through the Numerical Pain Scale (END), the following questionnaires were used to evaluate: Oswestry Disability Index (ODI), Survey of Pain Attitude (SOPA-B) and Fear Avoidance Beliefs Questionnaire (FABQ). Conclusion: The findings suggest that the application of elastic bandage following the progressive tension protocol promoted a reduction in disability index, pain and fear of movement, such outcomes can be considered clinically relevant, given the constant search for therapeutic techniques that provide improvement in the quality of life of patients with chronic LBP.

Keywords: Chronic pain; Low back pain; Elastic bandage; Physiotherapy.
\end{abstract}

\section{BACKGROUND}

Currently pain is defined by the International Association for the Study of Pain (IASP), as an unpleasant, associated sensory and emotional experience, or similar to that associated with a real or potential tissue injury. ${ }^{(1)}$ Therefore, when the pain that is established persists beyond physiological time, that is, more than three months, we can characterize it as a chronic pain. ${ }^{(2)}$

Thus, placing greater emphasis on the concept of low back pain (LBP), it is defined as a multifactorial musculoskeletal disorder that involves the presence pain, tension or stiffness in the region anatomically located between the last ribs and the gluteal line and which can be classified as specific when the is caused by already determined clinical conditions, or as nonspecific, when the pain-causing mechanism is not notably understood. ${ }^{(3-5)}$

This painful syndrome is one of the most frequent complaints found in physical therapy practice, reaching high epidemic levels where it is expected that approximately $80 \%$ of the world's population at some time of life will present with LBP, and about $40 \%$ of cases pain persists and becomes chronic. ${ }^{(3)}$ Its high prevalence explains the worrying condition that low back pain fits the public health aspect, as it is associated with a high rate of absenteeism in the work activity, disability and regular use of health services, generating high costs with treatment of patients with this condition and influencing aspects socioeconomic. ${ }^{(6)}$

The current literature points to several therapeutic methods for the relief of symptomatology and treatment of these patients, which involves the area of elastic bandage, resources of electrothermophototherapy, mobilizations, drug therapy, among others. ${ }^{(4)}$ An intervention that has been widespread in recent years is the elastic bandage, a technique developed in Japan in 1973 by Dr. Kenzo Kase, with the aim of providing patients with a therapeutic resource that muscles and other tissues to seek balance in the interval between sessions physiotherapy.

The relatively new method has been used as an additional resource in the therapeutic treatment in sports and has also been proposed to relieve pain of patients affected with chronic LBP. ${ }^{4,7)}$

The application of elastic bandage reduces the pressure of the skin on the myofascial tissue, from the stimulus given to the mechanoreceptors, thus altering the local blood flow, facilitating the reduction of the inflammatory process, assisting in the rehabilitation of the musculoskeletal system and providing support to joints, in addition to improving proprioception, increasing lymphatic drainage and reducing pain and 
fatigue by modifying biomechanical aspects of tissues and promoting improvement of the individual's functionality. ${ }^{(4,7)}$

According to, Morini et al, ${ }^{(8)}$ the effectiveness of the technique depends, in addition to the quality of the bandage, on the level of knowledge of the therapist in relation to the technique, because the professional who will make use of this resource must have mastery of their forms of application, as well as seek standardization based on scientific knowledge, not only assumptions. The author also provides evidence that to obtain significant strength for therapeutic effects the elastic bandage should be deformed above $75 \%$ from its original length, to all widths and lengths.

Even if the elastic bandage presents itself as an easy-to-use resource during therapy and its use can provide continuous stimulation to the patient even outside the time of the physiotherapy session, the studies available in the literature do not yet have a standardization of how to generate or develop tension suggested by the same articles, which hinders the effective reproduction of the technique, making it necessary to allow the effective use of such technique in physical therapy practice.

Therefore, the present study aimed to develop a pilot study in order to analyze the effects of the use of a progressive tension protocol with elastic bandage on disability, fear of effecting movement, coping with pain and pain level in an individual with nonspecific chronic LBP, aiming at the need to standardize the technique of application and use of elastic bandage in clinical practice, emphasizing that published studies addressing this theme are scarce and some are limited and/or controversial.

\section{METHODS}

A descriptive observational study was conducted, through a case study, approved by the Ethics Committee of University of Northern Paraná under a number of 3.059.113.

\section{Presentation of the case}

The present study had the participation of a 47-year-old female individual diagnosed with nonspecific chronic LBP through the disability questionnaire Oswestry Disability Index - ODI (severe intensity), pain at a level higher than 4 on the numerical pain scale, which was active as a caregiver for the elderly. The treatment protocol lasted a total duration of 10 weeks, and the individual met with the researcher once a week for reapplication of the bandage. In the first and last session, the same answered the following questionnaires: Oswestry Disability Index - ODI, Survey of Pain Attitude - SOPA-B, Fear Avoidance Beliefs Questionnaire - FABQ from and reported the level of pain of the subject, according to the Numerical Pain Scale - END.

\section{Oswestry Disability Index (ODI)}

The ODI questionnaire is commonly used and recommended to obtain disability measurements, an important component to be evaluated because it directs the therapist appropriate management of patients with spinal pain. Composed of a scale of 10 items, the first evaluates the intensity of pain, and the other, the consequences of pain in the daily life of the subject, and the score ranges from 0 (absence of disability) to 100 (maximum disability). ${ }^{(9)}$

\section{Survey of Pain Attitude (SOPA-B)}

SOPA-B is a questionnaire that evaluates and helps the therapist to understand the beliefs and attitudes related to pain of patients with chronic pain. It has in its structure 30 items that correspond to seven domains of beliefs and attitudes towards pain, being: medical cure, pain control, attention, disability, medication, emotion and physical damage, where the participant indicates whether he agrees or disagrees with each of the four statements. The scored answers correspond to 0 (totally false), 1 (false), 2 (neither true nor false), 3 (sometimes true), or 4 (always true). The score of each scale or domain calculated by the sum of the scores of the answers in each item, divided by the number of items of the answers in each item, divided by the number of items of the answers, so the average final score on each scale can range from 0 to 4 in this questionnaire. ${ }^{(10)}$

\section{Fear Avoidance Beliefs Questionnaire (FABQ)}

The FABQ specifically focuses on how the individual's beliefs and fear can affect questions about physical activity and work, contributing to their LBP and disability. Composed of 16 items in which the patient evaluates his agreement with each statement, where $0=$ totally disagree and 6 $=$ totally agree. It presents two subscales, working with 7 questions allowing maximum score of 42 and physical activity score with 4 questions and maximum score of 24 , totaling a maximum score of 96 , and the higher this score, the more strongly the beliefs of fear avoidance in the evaluated individual will be ingrained. ${ }^{(11)}$ 


\section{Numerical Scale of Pain}

The Numerical Pain Scale allows the patient to quantify the intensity of their pain at a given time having in its structure a numerical sequence from 0 to 10 , where point 0 indicates "absence of pain" and 10 represents "worst pain possible", numbers 2 to 9 indicators of intermediate pain levels felt. ${ }^{(12)}$

\section{Application of elastic bandage with progressive tension protocol}

For the application of the elastic bandage, the researcher used the anatomical measurements of the twelfth thoracic vertebra up to $5 \mathrm{~cm}$ below the upper posterior iliac spine (EIPS) for the control of tape size, measured in order to cover the entire lumbar spine region. Before application, the individual had the skin sanitized with $70 \%$ alcohol, seeking to maintain the durability of the tape, and removal of hair from the region with the same objective.

The progressive tension protocol followed the following order during the 10 weeks: 1 . Measuring the distance of the anatomical points between the twelfth thoracic vertebra and $5 \mathrm{~cm}$ below the post the superior iliac spine, which served as a reference for the application of the bandage throughout the protocol; 2 . The elastic bandage to be applied in the first session, had exactly the value of the distance between such anatomical points; 3. From the second session, $0.25 \mathrm{~cm}$ of the total bandage to be applied was gradually removed. That is, Week 1: tape size exactly the distance between the observed anatomical points; Week 2: tape size equal to previous week, minus $0.25 \mathrm{~cm}$; Week 3 : week 2 tape size, minus $0.25 \mathrm{~cm}$, and so consecutively until the tenth week.

The bandage was applied vertically on the transverse lumbar processes bilaterally, between the anatomical points of $\mathrm{T} 12$ and $5 \mathrm{~cm}$ below EIPS, with the individual seated, trunk in neutral position for application of the fixed point, and trunk flexion for the fixation of the moving point.

Noting that the tension of the elastic bandage will be given by the length of the same, since during the 10 weeks, the application will maintain the same anatomical points as a reference for inserting the fixation points of the tape.

\section{RESULTS}

Comparations were duly made between self-report questionnaires applied during the evaluations, in the first and last session, where it was observed that the individual participating in the study presented significant improvements in the scores scored when compared to the pre- and post-intervention moments.

As noted in Table 1, the individual participating in the study was classified in the ODI questionnaire in the first week with a very severe degree of disability (78\%) and presented after the end of the protocol minimum disability (10\%) scored in the last week, this outcome allows us to point out the importance of this decrease in the levels of disability to improve the quality of life of the individual under study, since the exacerbated ineptitude, prevalent in subjects with chronic low back pain, often excluded the possibility of work activity, practice of physical exercises, socialization and other dynamics related to the functionality of the individual.

There is also a significant improvement in the SOPA-B score in the 6 domains (control, emotion, disability, physical damage, solicitude and medical cure), when compared to the first and last evaluation, suggesting that the resource and protocol used caused improvements in these aspects to the individual.

In the $F A B Q$, there was a reduction in the domains of physical activity and work, a result that indicates a positive influence achieved through the use of elastic bandage with the protocol described in this study, in the promotion of improvements to the individual, both in the field of physical activity and in the work activity performed. In the measurement of pain with numerical pain scale, significant relief in the level of reported pain was obtained as a result, and in the first evaluation the referred pain was considerably high $^{(8)}$ and in the last one there was a significant decrease. ${ }^{(4)}$

\section{DISCUSSION}

Due to the high incidence and functional disability condition that chronic LBP promotes there are numerous interventions studied aiming at the management of symptoms, however, none has full efficiency for this pathology yet. Thus, the findings in this study collaborate with the knowledge already existing in the current literature about elastic bandage, efficiently and standardized during clinical practice.

The reduction in the level of disability of the participant evaluated with the ODI questionnaire is a finding that corroborates the data presented in the systematic review by Sheng et al, ${ }^{(13)}$ who addressed and collected significantly positive data for the use of elastic bandage in patients with 
nonspecific chronic low back pain, randomized clinical trials that used the same questionnaire as a result indicator. The authors Dionísio et al, ${ }^{(2)}$ in a study conclude that chronic low back pain is multifactorial and not determined only by biomechanical or musculoskeletal alterations, but also by biopsychosocial components that often favor scan ssurer clinical outcome for the patient, therefore, the results obtained through SOPA-B in the present study agree with these components that are related to the patient's pain, being a finding of great relevance in the context of clinical practice.

According to Leite et al, ${ }^{(14)}$ most patients with chronic LBP are socially affected, may present deficits in physical fitness due to severe pain make even functional training impossible and that such a situation can lead to anxiety and depression in these individuals, associated with the fact that feeling afraid and being influenced by beliefs of this aspect can generate a significant impact on the life of the worker subject, who is often depressed, anxious, disgruntled and afraid of being deprived of his job, agreeing with the findings of this study, that through the FABQ tool suggests that the beliefs and fears of patients with chronic LBP can negatively influence aspects of your life such as physical and work activity.

Ribeiro et al, ${ }^{(15)}$ point out in an observational study, with participants who present nonspecific chronic LBP, that the more intense the pain, the greater the disability that the individual will present in the activities performed and such analysis allows us to compare with the reduction of pain, evaluated through the numerical scale of pain, and we can still correlate the finding obtained in the ODI, already mentioned above, which assesses the level of disability of the individual.

Thus, the use of elastic bandage aggregates the options of effective therapies for the treatment of chronic LBP. Studies correlating elastic bandage or progressive tension protocol for chronic LBP are still scarce, since such a protocol involves a current and innovative technique. As described and analyzed, this technique proved to be efficient in the study presented, which encourages us to carry out new interventions to improve the results that have already been achieved.

\section{CONCLUSION}

Thus, it can be concluded that the application of elastic bandage with the use of the progressive tension protocol, it brought changes in the general health of the individual under study, as well as reduction of the rate of disability, pain and fear of effecting the movement. This fact is of great importance in the clinical context, because it directly reflects on the quality of life and consequently in the labor performance of the subject with nonspecific chronic LBP.

Authors' contributions: ACFTDA: conception and design of the study, survey, analysis and interpretation of the data and final approval of the version to be published. GAO: writing of the manuscript and critical review. MRS: analysis and interpretation of the data. TTDA: review and final approval of the version to be published. RCA: participated in the conception and coordination of the study, analysis and interpretation of the data.

Consent: Informed written consent was obtained from the patient for the publication of this case report. A copy of the written consent is available for review by the Editor of this journal.

Financial support: Nothing to declare.

Conflict of interest: Nothing to declare.

\section{REFERENCES}

1. Srinivasa NR, Daniel BC, Milton C, Nanna BF, Herta F, Stephen G, et al. Definição revisada de dor pela Associação Internacional para o Estudo da Dor: conceitos, desafios e compromissos. Associação Internacional para o Estudo da Dor (IASP). 2020.

2. Dionísio GH, Salermo VY, Padilha A. Sensibilização central e crenças entre pacientes com dores crônicas em uma unidade de atenção primária de saúde. BrJP. $2020 ; 3(1): 42-47$. http://dx.doi.org/10.5935/25950118.20200010.

3. Soares P, Cabral V, Mendes M, Vieira R, Avolio G, Vale RGS. Efeitos do Programa Escola de Postura e Reeducação Postural Global sobre a amplitude de movimento e níveis de dor em pacientes com lombalgia crônica. Rev. andal. med. deporte. 2016;9(1):23-28. http://dx.doi.org/10.1016/j.ramd.2015.02.00 5.

4. Lima HC, Luiz KRG, Magalhães MM, Silva DM, Reis MAS, Rodrigues EKCC, et al. Aplicação do Método Kinesio Taping e seus efeitos na redução da dor e no ganho da flexibilidade da coluna lombar em funcionários que trabalham sentados. Revista Eletrônica Acervo Saúde. 2019;11(16):e1385. 
http://dx.doi.org/10.5935/2595-

0118.20190044.

5. Desconsi MB, Bartz PT, Fiegenbaum TR, Candotti CT, Vieira A. Tratamento de pacientes com dor lombar crônica inespecífica por fisioterapeutas: um estudo transversal. Fisioter. pesqui. 2019;26(1):15$21 . \quad$ http://dx.doi.org/10.1590/18092950/17003626012019.

6. Adeed MAN, Costa LOP, Fukuda TY, Freitas $\mathrm{DG}$, Salomão EC, Monteiro RL, et al. Efficacy of adding the kinesio taping method to guideline-endorsed conventional physiotherapy in patients with chronic nonspecific low back pain: a randomised controlled trial. BMC musculoskelet. disord. (Online). 2013;14:301. http://dx.doi.org/10.1186/1471-2474-14301.

7. Kase K, Lemos TV, Dias EM. Kinesio Taping® Introdução ao Método e Aplicação Musculares. 2th ed. Pompeia - SP: Editora Andreoli; 2013.

8. Morini JN, Martini CS, Lopes-martins RAB, Canuto G, Silva RR, Scardovelli TA, et al. Mechanical Tensile Test Of The Body Adhesive Elastic Tape. International Journal of Recent Scientific Research. 2020;11(1):37150-37157.

http://dx.doi.org/10.24327//JRSR.

9. Fairbank JC, Pynsent PB. The Oswestry Disability Index. SPINE. 2000; 25(22):29402952. http://dx.doi.org/10.1097 / 00007632 200011150-00017.

10. Pimenta CAM, Kurita GP, Silva EM, Cruz DALM. Validity and reliability of the Survey of Pain Attitudes (SOPA-28 items) in the Portuguese Language. Rev. Esc. Enferm. USP. 2009;43(Spe):1070-1080. https://doi.org/10.1590/S008062342009000500011.

11. Abreu AM, Faria CDCM, Cardoso SMV, Salmela LFT. Versão brasileira do Fear Avoidance Beliefs Questionnaire. Cad. Saúde Pública. 2008;24(3):615-623. http://dx.doi.org/10.1590/S0102-

311 X2008000300015.

12. Reis LA, Torres GV. Influência da dor crônica na capacidade funcional de idosos institucionalizados. Rev. bras. enferm. 2011;64(2):274-280.

http://dx.doi.org/10.1590/S003471672011000200009.

13. Sheng $Y$, Duan Z, Qu Q, Chen W, Yu B. Kinesio Taping in treatment of chronic nonspecific low back pain: a Systematic Review and Meta-analysis. $\mathrm{J}$ rehabil. med. 2019;51(10):734-740.

http://dx.doi.org/10.2340/16501977-2605.

14. Leite AAAS, Santos LS, Araujo MO, Neto JLC. Dor Lombar e Exercício Físico: Uma Revisão Sistemática. Rev baiana saúde pública. 2015;39(2):442-459. http://dx.doi.org/10.22278/2318-2660.2015.

15. Ribeiro RP, Sedrez JA, Candotti CT, Vieira A. Relação entre a dor lombar crônica não específica com a incapacidade, a postura estática e a flexibilidade. Fisioter. pesqui. 2018;25(4):425-231.

http://dx.doi.org/10.1590/1809-

2950/18001925042018. 